\title{
Geometric morphometric analysis of cyclical body shape changes in color pattern variants of Cichla temensis Humboldt, 1821 (Perciformes: Cichlidae) demonstrates reproductive energy allocation
}

\author{
Paul Reiss ${ }^{1}$ and Thomas M. Grothues ${ }^{2}$
}

Previously recognized color and pattern variants of adult Cichla temensis in Amazon flood pulse river environments reflect the cycling of individuals through seasonal sexual maturity and spawning. Individuals also vary in shape from blocky to fusiform. To determine if shape differences are related to patterns of fat reserve deposition and utilization, and to quantify the relationship of shape with color and pattern variation and life history status, specimens in each of four previously defined grades of color and pattern variation were compared using geometric morphometric techniques. Progressive shape changes occurred between grades independent of sex and correlated to gonosomatic index (GSI). Thin plate spline deformation visualizations indicate that the observed shape differences are related to fat deposition patterns. The seasonal timing of shape change and its link to color pattern variation, sexual maturity and local water level conditions suggests a relationship between the physiological and behavioral characteristics of $C$. temensis and the cyclical flood pulse pattern of its habitat.

As variantes de cor e padrão previamente reconhecidos dos adultos de Cichla temensis em ambientes alagáveis amazônicos refletem o ciclo de indivíduos durante o período de maturidade sexual e desova. Indivíduos também variam na forma de oblonga a fusiforme. Para determinar se as diferenças de forma estão relacionadas aos padrões de deposição e utilização das reservas de gordura e quantificar a relação da forma com cor, variação de padrão e status da história de vida, espécimes de cada quatro níveis de cor e variação de padrão previamente definidos foram comparados usando técnicas de morfometria geométrica. Mudanças progressivas ocorreram na forma entre os níveis independentes do sexo e correlacionadas ao índice gonadossomático (IGS). Visualizações de finas deformações na placa da espinha indicam que as diferentes formas observadas estão relacionadas aos padrões de deposição de gordura. O período de mudança de forma e sua ligação com a variação do padrão de cor, maturidade sexual e as condições do nível da água local sugerem uma relação entre as características fisiológicas e comportamentais de Cichla temensis e o padrão de inundação cíclico do seu habitat.

Keywords: Fat reserves, Functional morphology, Gonadosomatic index, Hepatosomatic index, Physiology.

\section{Introduction}

Cichla is a genus that comprises 15 Neotropical species. All are large, diurnal and primarily piscivorous predators. Cichla temensis is the largest species with a natural range that consists primarily of blackwater flood pulse rivers with extremely variable seasonal environments (Val \& AlmeidaVal, 1995) in Brazil, Venezuela and Colombia. The species is economically important throughout its distribution, both in recreational (Myatt et al., 2005; Holley et al., 2008) and artisanal fisheries (Smith, 1981; Goulding, 1996).
Markedly different color and pattern variants of Cichla temensis coexist in their natural environments. The morphological variation within $C$. temensis was previously attributed to assumptions that the variants were different species, subspecies or an effect of sexual dimorphism (Braga, 1953; Myatt et al., 2005; Kullander \& Ferreira, 2006). A recent study has shown that the variants are all members of the same species and the differences in color and pattern among the variants are due to individual fish cycling through a series of changes correlated to seasonal gonad maturity (Reiss et al., 2012).

\footnotetext{
${ }^{1}$ Graduate Program in Ecology and Evolution, 14 College Farm Road, Rutgers University, New Brunswick, New Jersey 08902 , EUA. preiss@acuteangling.com (corresponding author)

${ }^{2}$ Rutgers University Marine Field Station, 800 c/o 132 Great Bay Blvd., Tuckerton, NJ 08087, EUA. grothues@marine.rutgers.edu
} 
Although color pattern variation occurs along a continuum, the common names used to describe the variants are based on the two distinct extremes (Winemiller, 2001; Reiss et al., 2012). The more brightly colored variant is known within the English-speaking sportfishing community as the Three-barred Peacock Bass (Myatt et al., 2005) and in Brazil as tucunaré açu (açu) (Kullander, 2003). Its general body color is yellowish-gold, with brightly colored fins and a pattern of three sharply demarcated dark vertical bars on the torso. The other extreme is called the Speckled Peacock Bass or tucunaré paca (paca). Dark and cryptically colored, its mostly grey or brown body color is dappled with a prominent series of light spots. Bright colors are absent. The three vertical bars are faint or almost invisible in relation to the spots and background color. Earlier work by Reiss et al. (2012) developed a color and pattern variation (CPV) scale, dividing the continuum of variation into four readily definable CPV grades (fig. 1 in Reiss et al. (2012)).

In addition to the previously analyzed color and pattern variations, the variants also differ in form. The paca extreme of variation (CPV Grade 1, fig. 1, Reiss et al. (2012)) appears fusiform relative to the açu extreme of variation (CPV Grade 4, fig. 1, Reiss et al. (2012)). The açu extreme presents what is best described as a block-like shape. It appears proportionately deeper bodied due to an apparent increased ratio of height to standard length (SL). The abdominal region appears to be extended beyond the skeletally constrained morphological features. Enlarged fleshy areas at the base of the anal fin and second dorsal fin further exacerbate the torso's squared-off appearance. Specimens in the defined grades between paca and açu (CPV grades 2 and 3) show intermediate levels of this shape change.
Cichla temensis form breeding pairs that guard their nest, eggs and fry for extended periods (Winemiller, 2001). They fast for up to two months during their reproductive period (Jepsen et al., 1999). Although some species of Cichla may spawn multiple times per year in lake and reservoir environments (Gomiero \& Braga, 2004), C. temensis likely spawn only once per year in their natural, flood-pulse river habitat (Jepsen et al., 1999), probably due to a combination of fluctuating availability of prey, spawning sites and potential forage for their fry. In consideration of these factors, Arrington et al., (2006) described Cichla temensis as a "capital" breeder (sensu Bonnet et al., 1998), requiring the deposition of energy stores in the form of lipid reserves prior to the initiation of its reproductive activity. There is seasonal variation in dorsal muscle lipid content in $C$. temensis from the Cinaruco River in Venezuela (Arrington et al., 2006). Inhamuns (2008) described the deposition of fatty tissue in dorsal muscle of Cichla during dry season conditions in Lago Janauaca, Amazonas, Brazil, also a flood pulse habitat of $C$. temensis. These studies suggest that in flood pulse environments, $C$. temensis begins to deposit reserves during falling water periods following the end of the rainy season, when prey become concentrated and most readily available. This seasonal variation in both the total body lipid content and the deposition of fat in specific areas in this species (Arrington et al., 2006; Inhamuns et al., 2009) further suggests that reserve deposition may be responsible for observed shape changes and may be related to cyclical color and pattern variation and the reproductive behavior of $C$. temensis in its natural habitat.

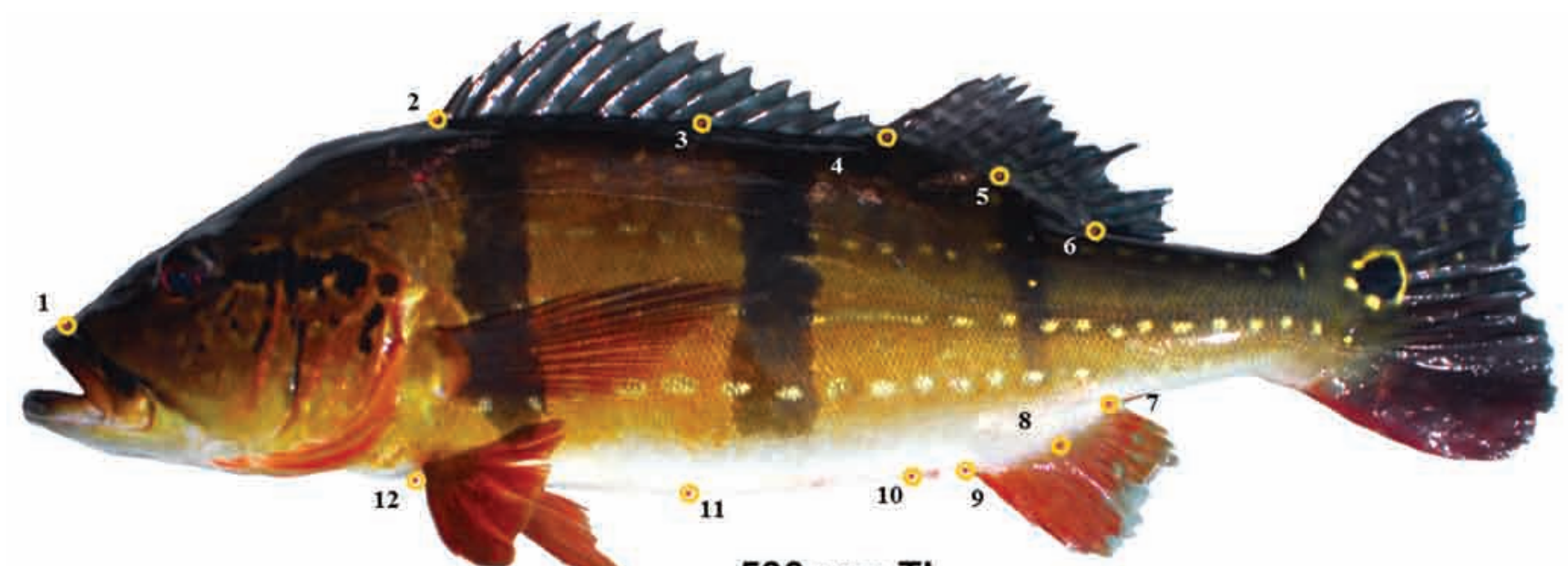

$530 \mathrm{~mm}$ TL

Fig. 1. Configuration of landmarks (red dot within yellow circles) as applied to all color pattern variation (CPV) grades of Cichla temensis. (1) the anterior point of the skull; (2) the anterior edge of the base of the first dorsal spine; (3) the center of the base of the $10^{\text {th }}$ dorsal spine; (4) the base of the first long ray of the second dorsal fin; (5) the base of the $9^{\text {th }}$ ray of the second dorsal fin; (6) the posterior point of termination of the second dorsal fin; (7) the posterior base of the anal fin; (8) the base of the $7^{\text {th }}$ anal fin ray; (9) the anterior insertion of the anal fin; (10) the cloaca; (11) the ventral termination of the scale row emanating from the insertion of the $10^{\text {th }}$ dorsal spine; (12) the ventral termination of the scale row emanating from the anterior point of the insertion of the pelvic fin. 
Changes in body shape are quantifiable when isolated from size and allometric effects. Shape, following the definition by Kendall (1977), is all the geometric information that remains when location, scale, and rotational effects are filtered out from an object. A recently developed method, geometric morphometry, provides more insightful analysis of shape than traditional multivariate analysis of a suite of linear measures ('trusses') (Parsons et al., 2003). By analyzing geometry among the locations of all points of consideration simultaneously, rather than serially pairwise, geometric morphometric techniques analyze shape variation that retains information on spatial covariation by using selected morphological "landmarks" (Rohlf \& Marcus, 1993). This is particularly relevant to the study described herein. In other Neotropical cichlids, geometric morphometrics applied to a common data set of similar but morphologically variable interspecific specimens, i.e. Amphilophus citrinellus and A. zaliosus, (Parsons et al., 2003) yielded strong evidence of morphological differences. In this application, where the differences to be examined are intraspecific, this fine degree of resolution is essential.

In this analysis, we apply geometric morphometric techniques to quantify the shape variation observed in C. temensis and we examine the hypothesis that there is a relationship between this shape change with CPV grade and cyclical seasonal environmental fluctuations.

\section{Materials and Methods}

Specimen Selection Criteria. The analyzed materials consist of uniformly posed photographs of live specimens. All were captured by angling with artificial lures by anglers traveling with a sport-fishing operation in the Amazon during falling and low water periods from 2009 through 2012. Fish were placed on a horizontal boat platform and a lateral image of the left side of each individual was captured using a digital camera (Nikon D200) held parallel to the platform, after which fish were returned to the water alive. A priori specifications of the image characteristics of this lens-camera system were examined to ensure that it would not produce visual distortions of shape (e.g. fish-eye effects or excessive parallax). Images were captured at a resolution of 10 megapixels. All photos were treated identically with Photoshop CS2 software to enhance clarity. An overall sample pool consisting of 824 specimen photographs in each of the CPV grades (see Fig. 1 in Reiss et al., 2012) was assembled from 7 widely separate habitat regions (rios Igapó Açu, Matupiri, Caures, Unini, Xeriuini, Urubaxi, Uneuixi) within the species' recognized range in Brazil in order to sample separate populations and eliminate the possibility of observing a local effect. The overall pool of specimen photographs was reviewed to eliminate those with improperly angled photos, flexed torsos, flattened fins, excessive glare and other mechanical deficiencies. Samples were then selected from the remaining pool, leaving selection of source location as a random effect.
Sizes of angler-captured fish were widely distributed (ranging from $<200 \mathrm{~mm}$ to $>920 \mathrm{~mm}$ standard length (SL); therefore, we defined specimen selection criteria to keep the analysis of body morphology size-independent. Juvenile $C$. temensis grow rapidly and undergo significant morphological change in their early life history (Kullander \& Ferreira, 2006). Fishes at larger size extremes display slower growth but often exhibit ontogenetic exaggeration of certain morphological features (Zelditch et al., 2004; von Bertalanffy, 1938). Because confounding allometric effects can occur in both of these size ranges (Richter et al., 2000) the specimen photographs used were restricted to images of individuals between $350 \mathrm{~mm}$ and $740 \mathrm{~mm}$. This range effectively also excluded specimens not capable of sexual maturity (Jepsen et al., 1999) and approximated the middle of the size range of the species (Myatt et al., 2005). Each of the four CPV grades (Reiss et al., 2012) was represented by 20 photographs with a relatively uniform distribution of specimen sizes, within the size range limitation and independent of sex. Grade 1 specimens averaged $507.6 \mathrm{~mm}$ with a Standard Deviation (SD) of 56.02. Grade 2 specimens averaged $518.7 \mathrm{~mm}$ with an SD of 83.8. Grade 3 specimens averaged $513.2 \mathrm{~mm}$ with an SD of 67.1. Grade 4 specimens averaged $510.4 \mathrm{~mm}$ with an SD of 96.3. ANOVA showed size distributions between CPV grades to be random and unordered $(p=0.97)$ further ensuring that no size trends confounded the shape analysis. The 80 selected specimens were randomly ordered for analysis.

Shape Analysis. Analysis was conducted using programs (referenced individually below) within the software suite tpsDig2, available from the Rohlf website at SUNY, Stony Brook, NY (http://life.bio.sunysb.edu/morph) (Rohlf, 2000). Shape variation was characterized using tpsDig2 v 2.05, a landmark-based geometric morphometric program (Adams et al., 2004; Zelditch et al., 2004). The eighty uniformly posed photographic specimens provided the raw shape data necessary to compare individuals among the four CPV grades. To summarize, beginning at CPV Grade 1 (paca extreme), they proceed stepwise through Grades 2 and 3 until reaching Grade 4 (açu extreme). Grade 2 specimens are those that are beginning to move from the paca form to the açu form and are distinguished by the appearance of distinct gold/brass color radiating from the lower edges of the interoperculum and suboperculum and extending into the preoperculum and operculum. Gold/ brass coloration extends into the body, encompassing the pelvic fins and the ventral lateral region. The dorsal and posterior trunk remains a darker grey or brown. Grade 3 specimens are approaching the açu form and are defined by a trunk dominated by gold/brass color below and extending to the lateral line. The dorsal fins and upper half of the tail remains dark while the anal and pelvic fins along with the ventral portion of the tail become a lighter, brighter red.

For ease of description, particularly when discussing shape extremes and spawning behavior throughout this 
work, the local term "paca" is used to refer to the most fusiform and non-sexually mature extreme of variation (CPV Grade 1), while "açu" refers to the most blocklike, brightly colored and sexually mature extreme (CPV Grade 4). The intermediate levels of variation do not have common local names and are instead referred to here by their CPV grades (2 and 3). The CPV grades as described in Reiss et al., (2012) are used when specifying numerical and statistical results and when referring to the continuum of CPV and shape variation (Table 1).

An initial analysis of the specimen's overall body form assessed variation in the overall shape characteristics of each CPV grade. Twelve two-dimensional landmarks on the left side of each fish were defined (Fig. 1). Locations were selected to encompass the central torso, including; (1) the anterior point of the skull; (2) the anterior edge of the base of the first dorsal spine; (3) the center of the base of the $10^{\text {th }}$ dorsal spine; (4) the base of the first long ray of the second dorsal fin; (5) the base of the $9^{\text {th }}$ ray of the second dorsal fin; (6) the posterior point of termination of the second dorsal fin; (7) the posterior base of the anal fin; (8) the base of the $7^{\text {th }}$ anal fin ray; (9) the anterior insertion of the anal fin; (10) the cloaca; (11) the ventral termination of the scale row emanating from the insertion of the $10^{\text {th }}$ dorsal spine; (12) the ventral termination of the scale row emanating from the anterior point of the insertion of the pelvic fin. To avoid confounding data points relative to the overall shape change, several anatomical structures were excluded. Points on the caudal peduncle and caudal fin were deemed unnecessary for this analysis and were excluded to avoid variation due to caudal fin damage or position of the tail during photography. The nuchal hump, a protrusion on the forehead of many reproductively active fishes, particularly Cichlids, is highly variable in form and occurs primarily in CPV Grade 4 males in C. temensis. It is outside of the area of overall shape change we studied and was excluded from this analysis by avoiding selection of any points defining it or occurring within it.
We rotated, translated and scaled landmark coordinates into alignment via generalized least squares superimposition, and described the variation in relative landmark positions using thin-plate spline visualization with tpsRegr following Bookstein (1991). Superimposed landmark configurations were then used to calculate partial warps (also with tpsRegr) for each of the CPV grades. Partial warps are analogous to bending energies necessary to deform a shape from a standard and thus describe morphological variation as variables in geometric morphometric analyses (Bookstein, 1991; Rohlf \& Marcus, 1993; Marcus et al., 1996).

Secondary Analyses. Based on the resulting thin-plate spline visualizations of overall shape and on potential fat deposition locations (Arrington, 2006; Inhamuns, 2008), a series of secondary analyses used landmarks and semilandmarks (software-generated secondary points dependent on the defined landmarks) to more closely assess areas other than the abdomen that appeared to generate large contributions to shape change. This ensured a second point of view that avoided the potential confounding effects of enlarged gonads, engorged stomachs, or liver size variation. This focused on two areas defined in the initial analysis; the shape of the fleshy bases of the second (soft) dorsal and the anal fin. Fixed landmarks defined the limits of the areas to be analyzed and sliding, equally spaced, semi-landmarks defined the outlines of the areas to be analyzed. The second (soft) dorsal fin was delimited by a landmark defined at the base of the first spine of the second dorsal fin and a second landmark at the point of termination of the second dorsal fin, identical to the corresponding landmark in the initial overall shape analysis. The tpsUtil curve creation function was then used to define a curve with 11 points and to convert these to semi-landmarks. Finally, the semi-landmarks were reviewed to confirm adherence to the structure's outline, adjusted as necessary to optimize position and then resampled to ensure even spacing. The same procedure was repeated with the anal fin using 8 points converted from the 2 primary landmarks.

Table 1. Guide to color pattern variation (CPV) grades and local names of Cichla temensis.

\begin{tabular}{|c|c|c|c|c|}
\hline CPV grade & Grade 1 & Grade 2 & Grade 3 & Grade 4 \\
\hline Common name & paca & n/a (called paca) & $\mathrm{n} / \mathrm{a}$ (called açu) & açu \\
\hline Description & $\begin{array}{l}\text { Cryptically patterned, dark } \\
\text { grey/brown background, } \\
\text { prominent series of light } \\
\text { spots in four loosely } \\
\text { delimited horizontal rows. } \\
\text { Total absence to trace of } \\
\text { gold/brass on ventral edge of } \\
\text { operculum and torso. Dorsal } \\
\text { fins dark with white spots, } \\
\text { recapitulating body pattern. } \\
\text { Ventral fins dark brown } \\
\text { to dark red. Postorbital } \\
\text { markings and vertical bars } \\
1,2 \text { and } 3 \text { almost invisible } \\
\text { against dark background. }\end{array}$ & $\begin{array}{l}\text { Significant gold/brass color } \\
\text { radiating from lower edges of } \\
\text { operculum extends to torso, } \\
\text { encompassing pelvic fins and } \\
\text { ventral lateral region anterior } \\
\text { to vertical bar } 2 \text {. Dorsal and } \\
\text { posterior torso dark grey/ } \\
\text { brown. Dorsal fins dark, } \\
\text { ventral lower fins become } \\
\text { red. Black vertical bars } 1,2 \\
\text { and } 3 \text { equal in prominence to } \\
\text { background of white spots. } \\
\text { Postorbital markings emerge } \\
\text { from background. }\end{array}$ & $\begin{array}{l}\text { Torso dominated by gold/ } \\
\text { brass color below lateral } \\
\text { line. Dorsal fins remain dark } \\
\text { while ventral fins become a } \\
\text { lighter, brighter red. Black } \\
\text { vertical bars become visibly } \\
\text { dominant on torso. Light } \\
\text { lateral spots remain visible, } \\
\text { but contrast against torso } \\
\text { diminished. Postorbital } \\
\text { markings now clearly visible. }\end{array}$ & $\begin{array}{l}\text { Brightly colored 3-barred } \\
\text { variant. Torso bright yellow } \\
\text {-gold color except for dorsal } \\
\text { extremes. Dorsal fins and } \\
\text { upper portion of caudal } \\
\text { fin blue ranging to bright, } \\
\text { electric blue. Ventral fins } \\
\text { bright red to orange. Vertical } \\
\text { black bars } 1,2 \text { and } 3 \text { sharply } \\
\text { demarcated, dominating } \\
\text { pattern. Light spots mostly } \\
\text { absent or trace. Postorbital } \\
\text { markings sharp and distinct. }\end{array}$ \\
\hline
\end{tabular}


Collateral analyses. Fat Analysis. As an alternative confirmation that fatty tissue was present in fleshy fin bases, a series of tissue samples from the fleshy portions of the anal fin and second dorsal fin bases were examined qualitatively by visual and microscopic examination. Tissue samples from 40 C. temensis individuals distributed through the range of color and pattern variation were obtained through donations of sacrificed specimens from local fishing guides.

Height/SL analysis. As a parallel test and simple confirmation of the shape changes measured by geometric morphometrics, we compared the ratio of height/SL in 200 previously collected specimens distributed among the four CPV grades using raw data collected a priori for Reiss et al. (2012).

Gonadosomatic and hepatosomatic index. The specimens used for gonadosomatic and hepatosomatic index measurements were the same 200 previously collected specimens described above (see Reiss et al., 2012). All were weighed then dissected. Liver, testes and ovaries were weighed on a digital scale to within 0.1 gram (Sartorius model GE7101 - precision 0.1 gram). GSI was then calculated following Le Cren, (1951) as GSI $=100$ (wet weight gonads in $\mathrm{g}$ )/(total body wet weight in $\mathrm{g}$ - wet weight gonads in g). HSI was calculated as HSI $=100$ (wet weight liver in $\mathrm{g}$ )/ (total body wet weight in $\mathrm{g}$ - wet weight liver in $\mathrm{g}$ ).

Statistical Analysis. The freeware software suite based on and supporting tpsDig2, available from the Rohlf website at SUNY, Stony Brook, NY (http://life.bio.sunysb. edu/morph) (Rohlf, 2000) was used to define landmarks, analyze the specimens and quantify results. To determine whether the amount of variation in the shape data set was appropriate to permit statistical analyses to be performed, tpsSmall (Rohlf, 2000) was used to assess the linear tangent space approximate to the non-linear Kendall's shape space. The landmarks were converted to shape coordinates by Procrustes superimposition (Rohlf, 2000). This procedure standardizes each specimen to unit centroid size, a sizemeasurement computed as the square root of the summed squared Euclidean distances from each landmark to the specimen's centroid and removes information about location and orientation from the raw co-ordinates.

Multivariate analyses were used to examine body shape differences. The thin-plate spline interpolating function was used to analyze residuals from the superimposition, producing principal warps. The distribution of mean shapes of each CPV grade in shape space was evaluated with Principal Component Analysis (PCA), called Relative Warp Analysis (RWA) when applied to Procrustes shape coordinates, using tpsRelW (Rohlf, 2000). Linear regression $(\alpha=0.05)$ tested the relationship between the relative magnitude of shape divergence and the grade of color and pattern variation in tpsRegr using Monte-Carlo permutation tests for differences between mean shapes.

\section{Results}

Geometric Morphometric Analysis and Thin Plate Spline Deformation. Shape differed significantly among the four CPV grades and correlated in magnitude with the rank of assigned CPV grade. Three shifts in body shape were most apparent: (1) overall body depth; (2) relative form of the fleshy area immediately below the soft-rayed second dorsal fin; (3) relative form of the fleshy area immediately above the anal fin. Body depth and fin base enlargement was greater in the açu form than the paca form. This shift produced the block-like body shape described in the açu form by deepening the central and posterior portion of the body, compared to the more fusiform shape of the paca form (Fig. 2).
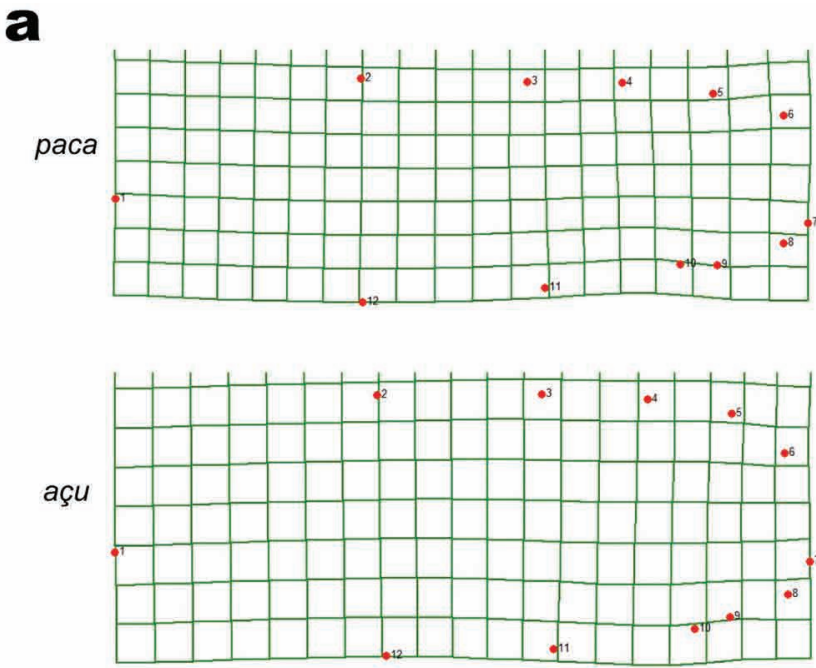

Mean Deformation - 3x Magnification

\section{b}
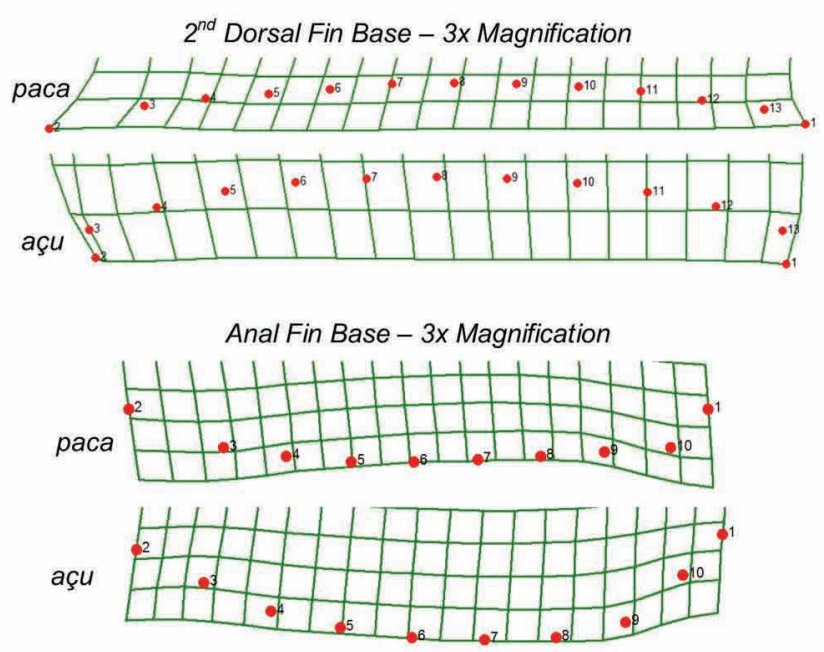

Fig. 2. Thin-plate-spline deformation grids depicting (a) overall body shape differences between extremes of CPV grades (magnified 3x); (b) the increase in area at the bases of the second dorsal and anal fins between extremes of CPV grades (magnified 3x). 
The second dorsal and anal fin bases, as defined by bordering landmarks and sliding semi-landmarks, increased significantly in area coinciding with increase in CPV grade. Deformation of the outlined fin bases demonstrated an increase in total area where reserves are known to be deposited and contributed to the overall shape change evidenced by the initial analysis.

Relative Warps Analysis. A large fraction (20.59\%) of the variance in biologically significant individual body shape differences can be explained by the first principal component of the relative warps analysis (Table 2; Fig. 3). The effect of CPV grade on the first principal component was significant (Roy's Maximum Root statistic $=3.4993, \mathrm{Fs}=10.323 \mathrm{df} 1$ $=20, \mathrm{df} 2=59, \mathrm{P}<0.001)$ as it was on the total variance for which it accounted (Pillia's trace statistic $=0.7777$, Fs $=10.323, \mathrm{df} 1=20, \mathrm{df} 2=59, \mathrm{P}<0.001)$. Individuals with positive amplitude on the first relative warp are increasingly deep bodied and blocky. The trajectory of shape change with increasing CPV grade is significant (Table 2). CPV Grade 1 (paca) specimens had a relatively slim overall body with a fusiform shape. Grade 2 and 3 specimens were progressively blockier. CPV Grade 4 (açu) color specimens were characteristically deep-bodied, with a relatively squared off torso. Fig. 2 shows a visualization of shape differences among variants in terms of deformation grids.

Table 2. Relative Warp Analysis of Cichla temensis. Singular values (SV) and percent explained for each relative warp (principle axis). The first relative warp was significantly different from random (v2 1/4 7.6539, 2.1387; $\mathrm{P}<0.05$ ), indicating that much of the biologically significant individual body shape differences can be explained on this component.

\begin{tabular}{cccc}
\hline $\begin{array}{c}\text { Relative warp } \\
\text { (principle axis) }\end{array}$ & $\begin{array}{c}\text { Singular value } \\
\text { (SV) }\end{array}$ & \% explained & Cumulative \% \\
\hline 1 & 0.17896 & $20.59 \%$ & $20.59 \%$ \\
2 & 0.17634 & $20.00 \%$ & $40.59 \%$ \\
3 & 0.15128 & $14.72 \%$ & $55.31 \%$ \\
4 & 0.12616 & $10.24 \%$ & $65.54 \%$ \\
\hline
\end{tabular}

Collateral Analyses. Fat. Examination of tissue samples from the fleshy portions of the anal fin and second dorsal fin bases showed the presence of fatty tissues. Microscopic analysis showed the presence of adipose tissue and heterogeneous adipocytes containing fat droplets in all samples (Dettmeyer, 2011). Macroscopic examination assisted by heating of fin base tissues showed the presence of a mixture of muscle and fatty tissues.

Height/SL analysis. The average height/SL ratio increased significantly with CPV grade; 0.2694 for Grade 1 (paca), 0.2725 for Grade 2, 0.2771 for Grade 3 and 0.2822 for Grade 4 (açu) (ANOVA df $=119, F=5.323, p<0.002)$. This result supports the shape change trend shown by geometric morphometric analysis (Fig. 4).

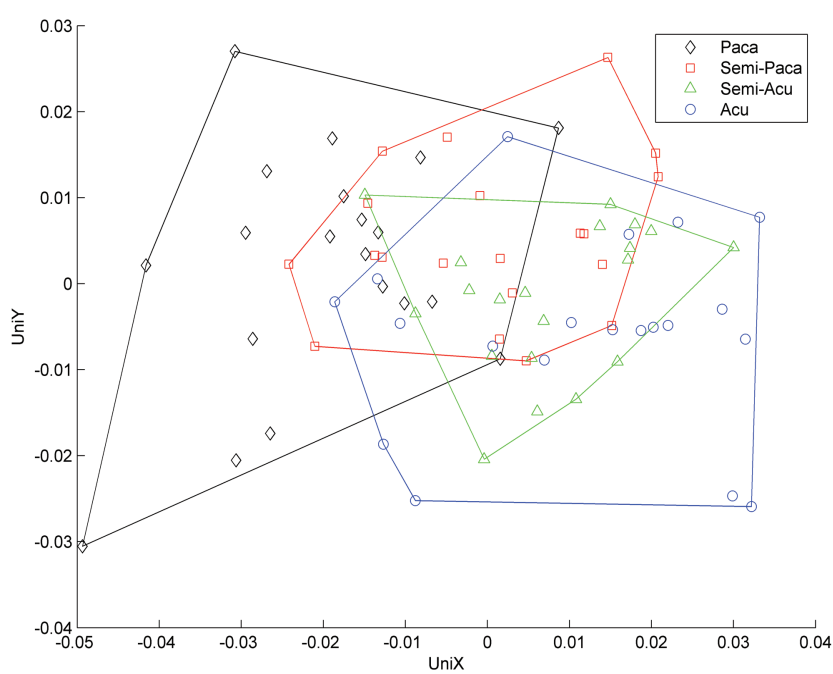

Fig. 3. Biplot of the uniform components in each direction (UniX and UniY) of morphometrical differences in 80 specimens of Cichla temensis in 4 color variation patterns (CPV) as measured by 9 Thin Plate Spline (TPS) distortion variables (V1-V9). Colored numbers indicate the CPV grade of individuals. The total spread of scores among individuals of each CPV are indicated by an envelope (solid line polygon) calculated as the minimum convex hull for that group. Position in the plot relative to other individuals indicates the degree of similarity in morph. Vectors point in the direction of gradient change for that TPS variable and the magnitude indicates the strength of the gradient. Angles between vectors indicate the TPS interset correlations.

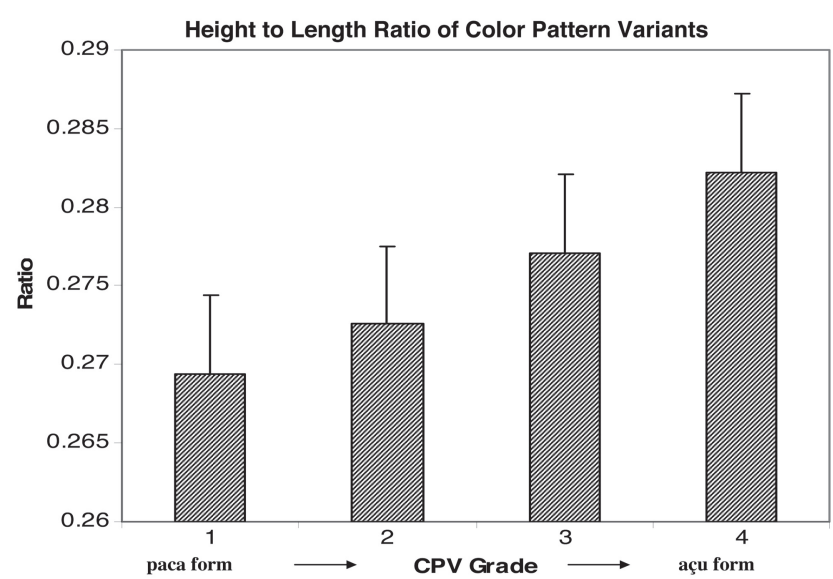

Fig. 4. Height to length ratio of color pattern variants of Cichla temensis. The average height/SL ratio increased with CPV grade from a low of 0.2694 for CPV Grade 1 (paca), 0.2725 for CPV Grade 2, 0.2771 for CPV Grade 3 and 0.2822 for CPV Grade 4 (açu).

\section{Discussion}

Geometric morphometric analysis confirms a progressive shape change in $C$. temensis. Much of the variation was due to fatty reserve deposition in specific areas known to be potential reserve storage sites (Arrington, 
2006) and which were observed in this study to contain adipose cells, implying that increased energy storage in these tissues was responsible for the change. Shape change is correlated with the degree of CPV progressing from the relatively slim, hydrodynamic form of the non-reproductive paca (CPV Grade 1) extreme to the increasingly deeper body form of specimens as they approach the açu (CPV Grade 4) extreme of color pattern variation. GSI is at its maximum in the açu form. The correlation of shape change with CPV grade indicates that maximal reserve deposition occurs immediately prior to spawning and the ensuing post-spawning period of fry guarding when adults cease feeding for extended periods. Spawning occurs once per year in lowlands flood pulse rivers (Jepsen et al., 1996; Winemiller, 2001; Hoeinghaus, 2006), indicating that these linked changes are cyclical. They correspond to the temporal patterns of large-scale habitat variation in the Amazon as described by Junk (1989) and have a close relationship to the flood-pulse system's cyclical water level changes (Jepsen et al., 1999), suggesting functional morphological changes linking the mechanical aspects of anatomical form to organismal behavior.

Many fish species exhibit marked morphological changes during sexual maturation cycles (reviewed in Robinson \& Wilson, 1994; Smith \& Skúlason, 1996; Taylor, 1999; Jonsson \& Jonsson, 2001). Cichla temensis changed shape along the CPV gradient and CPV grade is directly correlated with GSI in both males and females (Reiss et al., 2012). Gonad size is a relatively small component of total size in C. temensis, especially in males, where maximum gonadosomatic index remains below $0.35 \%$. Female GSI can reach $2.5 \%$ (Reiss et al., 2012). Considering the demonstrated relationships between CPV, shape change and reserve deposition, the resulting inference that reserve deposition and GSI proceed in relation to each other is supported. This is in keeping with the description of C. temensis as a "capital" breeder. It also supports the likelihood that the shape changes as $C$. temensis matures toward spawning during the yearly flood pulse cycle reflect the addition of reserves that will be depleted during the parents' extended post-spawning fast. Jepsen et al. (1999) has described this period as a "physiological winter". Cichla temensis' relatively low investment of reserves in gamete volume (i.e. as compared with egg scattering species) contrasts with the relatively high investment of reserves expended during the long fry-guarding period. These linked cyclical changes, occurring in correspondence to temporal patterns of habitat change, demonstrate a close affinity with the flood-pulse system's cyclical water level changes. Further analyses might include an assay of how the specific amount of fat deposited relates to specimen size or age, or perhaps a comparison of how this effect appears in other flood pulse Cichlids. Ultimately, a synthesis of this data and other information related to the timing of environmental, physiological and behavioral changes may help to more clearly elucidate this effect.
Liver and reserves. Although the liver is recognized as an important site of lipid deposition and reserve storage in fishes (Larson, 1991; Helfman et al., 1997), data analyzed during this study pointed to a dichotomy between reserves used for gametogenesis and for maintenance, justifying further analysis of the phenomenon. This study initially focused on the effect of corporal fatty reserve deposition (in the muscles, mesentery and fin bases) in specimens without direct consideration of liver reserves for several reasons; first, the geometric morphometric analysis in this study was based on the use of uniformly positioned photographs acting as specimens. Photographic specimens, of course, do not lend themselves to dissection and analysis of internal organs. Second, although patterns of reserve deposition (specifically regarding liver reserve versus alternate corporal reserve deposition) vary with species and life history parameters, the literature shows that fishes whose reproductive period does not coincide precisely with periods of low food availability or high energy requirements may have offset periods of reserve deposition and consumption between the liver and corporal deposits. When reproductive maturation is disengaged from migration, maintenance or periods of minimal food availability, increases in hepatosomatic index (HSI) are not necessarily synchronized with increases in corporal reserve deposition or utilization (Larson, 1991; Schaan et al., 2009). Further it is suggested that materials essential to gametogenesis are stored in the liver(Craig etal., 2000; Regost et al., 2001) and that body fat is not metabolically essential for reproduction; rather it is used primarily for maintenance during low food or high energy consumption periods, such as winter in temperate zone fishes (Larson, 1991). This may be the case in C. temensis during fry guarding.

In C.temensis inaflood pulseenvironment, gametogenesis generally occurs during the period of greatest food abundance while maintenance needs (the period of fasting associated with fry rearing) occurs only after gametes have been expended (Jepsen et al., 1999; Winemiller, 2001). Thus, liver and corporal reserves are not utilized in a synchronized manner; rather they are disengaged and complementary. Inhamuns et al. (2009) indicated that Cichla sp. contained different ratios of lipid components at different times during the flood pulse and attributed this to differing metabolic and reproductive needs. Although Arrington et al. (2006) found a significant relationship between lipid liver content and the mesenteric fat index, analysis of the relationship between HSI and GSI in C. temensis segregated by CPV grade, shows that after an initial period of increase in both indices, HSI stabilizes and then drops as GSI increases to its maximum. This effect is even more pronounced in females and is similar to that shown in another Neotropical flood pulse river species, Brachyhypopomus draco (Schaan et al., 2009). In summary, as $C$. temensis individuals approach the açu form and gametes and gonads mature, HSI begins to decrease while corporal reserves continue to increase. Açu specimens (CPV Grade 4) with the highest mean GSI showed the lowest mean HSI (Fig. 5). 


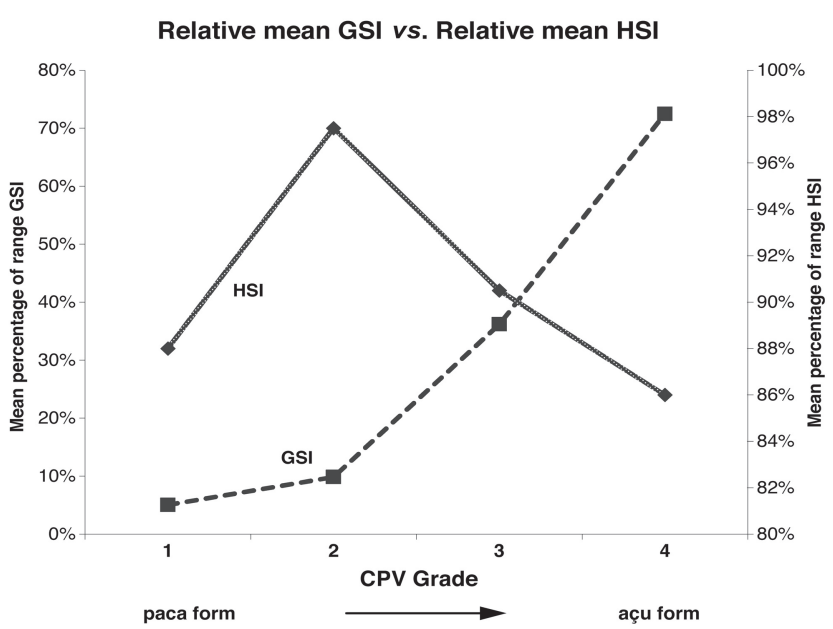

Fig. 5. Relative mean GSI vs. relative mean HSI of color pattern variants of Cichla temensis. Points for GSI represent the mean value for each CPV grade as compared to the range encountered. Points for HSI represent the mean value for each CPV grade compared to the range encountered.

Likegonad size, livermass is a relatively small component of total mass in C. temensis, with hepatosomatic indexes ranging from $0.4 \%$ to $1.6 \%$ (Reiss et al., 2012). Since these organs are contained within the body cavity, liver volume and gonad volume both contribute to the overall torso shape as analyzed herein and are thus effectively incorporated into the gross shape change. Since their size increases are disjunctive and negatively related when at maximum, they likely tend to balance each other's contribution to shape change as spawning approaches. Jepsen et al. (1999) also noted that specimens collected with mature gonads never contained food in their stomachs, essentially eliminating engorged abdomens as a factor in increase in body depth in the açu (CPV Grade 4) form. Hence, all of these considerations are indirectly included in the gross shape analysis. They are irrelevant to the secondary analyses of fin base fat deposition sites.

Nuchal hump. Fontenele (1948) described the nuchal hump that occurs in sexually mature $C$. temensis males. Gomiero \& Braga (2004) noted its appearance in males shortly prior to spawning. Their histological examination showed that it contained large quantities of lipid in the form of oil droplets that were depleted after spawning. Barlow (2000) and Bleick (1975), however, found that the hump in other Cichlids is caused by local edema, diluting preexisting fat. In either case, this seasonal secondary sexual characteristic is not addressed in this analysis for several reasons. Because of the hump's irregular form and a lack of bordering or defining primary landmarks, it proved impractical to assess consistently with geometric morphometric techniques. Additionally, it occurs only in CPV Grade 4 specimens and is essentially restricted to mature males, leaving it a somewhat sporadically appearing factor in the overall body shape of specimens. It is, however, an interesting phenomenon and in light of the timing of its appearance merits consideration as a component of the entire suite of C. temensis cyclical physiological changes.

Cyclicality. The data used in this study were collected during and around regional dry seasons. Due to access, water level and humane treatment considerations, data of this type is not readily available from high water periods (Reiss et al., 2012). Further, Cichla have been shown to modify their behavior and reproductive strategies in reservoirs and non-flood-pulse conditions (Brafield \& Llewelyn, 1982; Chellapa et al., 2003), making it likely that studies in artificial environments may be inapplicable (Zaret, 1980). Therefore, it cannot be known precisely how shape variation proceeds during the high water period until a study is performed that observes individuals throughout a full year's cycle in a flood pulse environment.

In spite of the lack of shape data collected in high water, several considerations identified regarding the CPV cycle (Reiss et al., 2012 ; Chellapa et al., 2003), Cichla reproductive patterns and fry-guarding fasts (Jepsen et al., 1999; Gomiero \& Braga, 2004) and the large seasonal variation in dorsal muscle lipid content found by Arrington et al. (2006) make it likely that the block-like shape of the açu individuals returns to the hydrodynamic shape of the paca after spawning and rearing is completed. Considered together with the larger shape variance found in CPV Grades 1 and 4, this information supports a cyclical process returning the shape characteristics of açu variants to the paca form.

The cyclical morphological, behavioral and physiological changes demonstrated by Cichla temensis in its native habitat appear to be closely associated with the timing of predictable environmental changes. The capability of expressing and utilizing these characters in temporal accord with cyclical environmental fluctuations is likely an adaptation to the species' natural flood-pulse environment.

\section{Acknowledgements}

We thank Acute Angling, Inc., Hillsborough, NJ, U.S.A. for providing funding and logistical support. We thank the many patient sportfishermen who willingly and helpfully cooperated with our specimen collection protocols and NG Turismo Ltda., Manaus, AM, Brazil, for providing field personnel. Special gratitude is reserved for Wellington Araujo Melo and Norberto Guedes da Silva. We thank Ken Able, Izeni Farias and Tomas Hrbek for their suggestions and guidance. Additional assistance was provided by Rutgers University, New Brunswick, NJ, USA; Department of Biology, Universidade Federal do Amazonas, Manaus, Brazil; and the Instituto Nacional de Pesquisas da Amazônia (INPA), Manaus. Specimens were collected under permanent license (MMA IBAMA 11325-1). This paper represents Rutgers University, Institute of Marine and Coastal Sciences Contribution No. 2014-7. 


\section{References}

Adams, D. C., F. J. Rohlf \& D. E. Slice. 2004. Geometric morphometrics: ten years of progress following the 'revolution'. Italian Journal of Zoology, 71: 5-16.

Arrington, D. A., K. O. Winemiller, B. K. Davidson \& C. A. Layman. 2006. Influence of life history and seasonal hydrology on lipid storage in three Neotropical fish species. Journal of Fish Biology, 68: 1347-1361.

Barlow, G. W. 2000. The cichlid fishes: nature's grand experiment in evolution. Cambridge, Perseus Books, 352p.

Bertalanffy, L. Von. 1938. A quantitative theory of organic growth (Inquiries on growth laws. II.). Human Biology, 10: 181-213.

Bleick, C. R. 1975. Hormonal control of the nuchal hump in the cichlid fish Cichlasoma citrinellum. General and Comparative Endocrinology, 26: 198-208.

Bonnet, X., D. Bradshaw \& R. Shine. 1998. Capital versus income breeding: an ectothermic perspective. Oikos, 83: 333-342.

Bookstein, F. L. 1991. Morphometric tools for landmark data: geometry and biology. New York, Cambridge University Press, 435p.

Brafield, A. E. \& M. J. Llewellyn. 1982. Animal energetics. Glasgow, United Kingdom, Blackie Books, 168p.

Braga, R. 1953. Crescimento de tucunaré pinima, Cichla temensis (Humboldt) em cativeiro (Actinopterygii: Cichlidae). Dusenia, 4: 41-47.

Chellappa, S., M. R. Camara, N. T. Chellappa, M. C. M. Beveridge \& F. A. Huntingford. 2003. Reproductive ecology of a Neotropical cichlid fish, Cichla monoculus (Osteichthyes: Cichlidae). Brazilian Journal of Biology, 63: 17-26.

Craig, S. R., D. S. Mackenzie, G. Jones \& D. M. Gatlin. 2000. Seasonal changes in the reproductive condition and body composition of free-ranging red drum, Sciaenops ocellatus. Aquaculture, 190: 89-102.

Dettmeyer, R. 2011. Forensic histopatholgy fundamentals and perspectives. Heidelberg, Springer Verlag, 454p.

Fontenele, O. 1948. Um caráter sexual secundário extragenital nos tucunarés (Actinopterygii, Cichlidae). Revista Brasileira de Biologia, 8: 185-188.

Goulding, M., N. J. H. Smith \& D. J. Mahar. 1996. Floods of fortune - ecology and economy along the Amazon. New York, NY, Columbia University Press, 193p.

Gomiero, L. M. \& F. M. S. Braga. 2004. Reproduction of species of the Genus Cichla in a reservoir in Southeastern Brazil. Brazilian Journal of Biology, 64: 613-624.

Helfman, G., B. B. Collette \& D. E. Facey. 1997. The Diversity of fishes. Oxford, UK, Blackwell Science, 527p.

Hoeinghaus, D. J., K. O. Winemiller, C. A. Layman, D. A. Arrington \& D. B. Jepsen. 2006. Effects of seasonality and migratory prey on body condition of Cichla species in a tropical flood- plain river. Journal of Freshwater Fish, 15: 398-407.

Holley, M. H., M. J. Maceina, M. Thomé-Souza \& B. R. Forsberg. 2008. Analysis of the trophy sport fishery for the speckled peacock bass in the Rio Negro River, Brazil. Fisheries Management and Ecology, 15: 93-98.

Inhamuns, A. J. \& M. R. Bueno Franco. 2008. EPA and DHA quantification in two species of freshwater fish from central Amazonia. Food Chemistry, 107: 587-591.
Inhamuns, A. J., M. R. Bueno Franco \& W. S. Batista. 2009. Seasonal variations in total fatty acid composition of muscles and eye sockets of tucunaré (Cichla sp.) from the Brazilian Amazon area. Food Chemistry, 117: 272-275.

Jepsen, D. B., K. O. Winemiller, D. C. Taphorn \& D. Rodriguez Olarte. 1999. Age structure and growth of peacock cichlids from rivers and reservoirs of Venezuela. Journal of Fish Biology, 55: 433-450.

Jonsson, B. \& N. Jonsson 2001. Polymorphism and speciation in Arctic char. Journal of Fish Biology, 58: 605-638.

Junk, W. J., P. B. Bayley \& R. E. Sparks. 1989. The flood pulse concept in river-floodplain systems. Canadian Special Publication of Fisheries and Aquatic Sciences, 106:110127.

Kendall, D. 1977. The diffusion of shape. Advances in Applied Probability, 9: 428-430.

Kullander, S. O. 2003. Family Cichlidae. Pp. 605-655. In: Reis, R. E., S. O. Kullander \& C. J. Ferraris, Jr. (Eds.). Check list of the freshwater fishes of South and Central America. Porto Alegre, Edipucrs.

Kullander, S. O. \& E. J. G. Ferreira. 2006. A review of the South American cichlid genus Cichla, with descriptions of nine new species (Teleostei: Cichlidae). Ichthyological Exploration of Freshwaters, 17: 289-398.

Larson, R. J. 1991. Seasonal cycles of reserves in relation to reproduction in Sebastes. Environmental Biology of Fishes, 30: $57-70$.

Marcus, L. F., M. Corti, A. Loy, G. J. P. Naylor \& D. E. Slice (Eds.). 1996. Advances in morphometrics. New York, Plenum, 587p. NATO ASI Series A: Life Sciences, v. 284.

Myatt, M. J., D. Hartman, A. E. Gray, L. Arico, G. M. Morchower \& J. Schratweiser (Eds). 2005. 2005 World Record Game Fishes. Dania Beach, Florida, The International Game Fish Association, 407p.

Parsons, K. J., B. W. Robinson \& T. Hrbek. 2003. Getting into shape: An empirical comparison of traditional truss-based morphometric methods with a newer geometric method applied to New World Cichlids. Environmental Biology of Fishes, 67: 417-431.

Regost, C., J. Arzel, M. Cardinal, M. Laroche \& S. J. Kaushik. 2001. Fat deposition and flesh quality in seawater reared, triploid brown trout (Salmo trutta) as affected by dietary fat levels and starvation. Aquaculture, 193: 325-345.

Reiss, P., K. W. Able, M. S. Nunes \& T. Hrbek. 2012. Color pattern variation in Cichla temensis (Perciformes: Cichlidae): Resolution based on morphological, molecular, and reproductive data. Neotropical Ichthyology, 10: 59-70.

Richter, H, C. Luckstadt, U. Focken \& K. Becker. 2000. An improved procedure to assess fish condition on the basis of length-weight relationships. Archive of Fishery and Marine Research, 48: 255-264.

Robinson, B. W. \& D. S. Wilson. 1994. Character release and displacement in fishes: a neglected literature. American Naturalist, 144: 596-627.

Rohlf, F. J. \& L. F. Marcus. 1993. A revolution in morphometrics. TREE, 8: 129-132.

Rohlf, F. J. 2000. On the use of shape spaces to compare morphometric methods. Hystrix, 11: 8-24.

Schaan, A. B., J. Giora \& C. B. Fialho. 2009. Reproductive biology of the Neotropical electric fish Brachyhypopomus draco (Teleostei: Hypopomidae) from southern Brazil. Neotropical Ichthyology, 7: 737-744. 
Smith, N. J. H. 1981. Man, fishes, and the Amazon. New York, NY, Columbia University Press, 180p.

Smith, T. B. \& S. Skúlason. 1996. Evolutionary significance of resource polymorphisms in fishes, amphibians, and birds. Annual Review of Ecology and Systematics, 27: 111-133.

Taylor, E. B. 1999. Species pairs of north temperate freshwater fishes: evolution, taxonomy, and conservation. Reviews in Fish Biology and Fisheries, 9: 299-324.

Val, A. L. \& V. M. F. de Almeida-Val. 1995. Fishes of the Amazon and their environment: physiological and biochemical aspect. Berlin, Germany, Springer-Verlag, 224p.

Winemiller, K. O. 2001. Ecology of peacock cichlids (Cichla spp.) in Venezuela. Journal of Aquariculture and Aquatic Sciences, 9: 93-112.
Zaret, T. M. 1980. Life history and growth relationships of Cichla ocellaris, a predatory South American cichlid. Biotropica, 12: 144-157.

Zelditch, M. L., D. L. Swiderski, H. D. Sheets \& W. L. Fink. 2004. Geometric morphometrics for biologists: a primer. San Diego, Elsevier Academic Press, 456p.

Submitted February 21, 2014

Accepted October 26, 2014 by William Crampton

Published March 31, 2015 